\title{
Safe to Engage: Chronic Illness and Organisational Citizenship Behaviours at Work
}

\author{
Andrea Kirk-Brown and Pieter Van Dijk \\ Monash University, Australia
}

\begin{abstract}
T he aim of this study is to extend current models of employee work engagement to include chronic illness in order to better understand and predict workforce participation for the chronically ill. Using a sample of 604 participants, the current study examined the relationship between work engagement, perceptions of psychological safety at work and the performance of organisational citizenship behaviours for employees with chronic illness $(N=92)$ compared to a referent group of general employees $(N=512)$. Results indicate that for chronically ill employees, psychological safety partially mediates the relationship between engagement and the performance of organisational citizenship behaviours. These results suggest that the development of a workplace environment characterised by feelings of safety, interpersonal trust and mutual respect will foster the performance of engaged work behaviours for a group of employees vulnerable to the experience of a reduced sense of personal efficacy in the workplace and consequent premature retirement.
\end{abstract}

Keywords: chronic illness, psychological safety, work engagement, organisational citizenship behaviours

Current models of employee stress have broadened from a focus on workplace deficiencies to better understanding the conditions that promote workplace wellbeing and positive job performance outcomes. While models of psychosocial adaptation to chronic illness (CI) acknowledge the key role of the workplace as a contextual influence in the adaptation process (Bishop, 2005; Livneh, 2001), the mechanisms that underlie and promote positive work experiences for employees with chronic illness are poorly understood. A number of studies have reported higher levels of work-related impairment for CI employees than for non-CI comparison groups (Collins et al., 2005; Dean, et al., 2005); however, evaluations of psychosocial factors related to workplace well-being are comparatively rare. Chronic illness has been labelled as the overlooked dimension of workplace diversity (Beatty \& Joffe, 2006), with increasing recognition that anti-disability discrimination measures are necessary but not sufficient to foster the workplace engagement of this group of vulnerable employees (Banks \& Lawrence, 2006).

Work engagement has been defined as a positive, fulfilling, affective-motivational state of work-related wellbeing that is the antipode of job burnout (Leiter \& Bakker, 2010; Maslach, Schaufeli, \& Leiter, 2001; Schaufeli \& Bakker, 2004). There is a reciprocal and positive relationship between the provision of job resources, such as social support or job autonomy, and work engagement (Demerouti, Bakker, Nachreiner, \& Schaufeli, 2001; Salanova, Schaufeli, Xanthopolou, \& Bakker, 2010). Associations have been consistently demonstrated between levels of engagement (conceptualised as the three dimensions of vigour, dedication and absorption) and positive organisational outcomes such as service quality as rated by customers (Salanova, Agut, \& Peiró, 2005), intention to leave and organizational commitment (Schaufeli \& Bakker, 2004), and

Address for correspondence: Dr Andrea Kirk-Brown, Department of Management, Monash University, PO Box 1071, Narre Warren VIC 3805, Australia. E-mail: andrea.kirk-brown@monash.edu

Kirk-Brown, A. \& Van Dijk, P. (2011). Safe to engage: Chronic illness and organisational citizenship behaviours at work. International Journal of 
organisational citizenship behaviours (OCBs) (Saks, 2006). The translation of the affective-motivational state of work engagement into positive work behaviours allows employees to make full use of their skills and abilities when performing tasks and developing their careers (Leiter \& Bakker, 2010). The psychological mechanisms that facilitate the translation of positive cognitive affective work states, such as engagement, into desirable work behaviours may, however, involve higher levels of personal resource risk for employees with chronic illness when compared to non-CI employees. Studies of workforce participation for the chronically ill indicate that this group of employees is subject to a declining sense of psychological safety when considering their role, participation at work, and continuing employment in their organisation (Roessler, 2003; Roessler, Turner, Robertson, \& Rumrill, 2005;Vickers, 2008).

The aim of this study is to examine the potential mediating role of perceptions of psychological safety at work in the relationship between work engagement and the performance of $\mathrm{OCBs}$ for employees with chronic illness. We argue that the provision of a psychologically safe working environment for the chronically ill will strengthen employees' perceived personal resource pool, which in turn will lead to a greater likelihood that employees will seek opportunities to risk resource investment in the voluntary performance of job-related tasks and behaviours that transcend specified role requirements (OCBs). The examination of nonsymptom-related reasons surrounding participation in organisational activities such as OCBs offers an additional route to facilitate the job retention of the chronically ill.

\section{Workforce Participation for the Chronically III}

The evaluation of work life for the chronically ill is different for those who do not suffer any level of disability or continuing illness. Recent reports indicate that chronic illness not only severely impacts individual functioning at work but also the workforce in general. A report by the Australian Institute of Health and Welfare (2009) estimates that 540,000 person-years of participation of full-time employment are lost to the workforce annually due to chronic illness, and that the chronically ill are 60\% (adjusted for age and sex) less likely to participate in the workforce than those without chronic diseases. These high dropout rates indicate that that there is much to be understood in facilitating the retention of chronically ill employees.

Models of psychosocial adaptation to chronic illness and disability address the impact of CI over a range of life domains, with employment being one of the domains most consistently identified as contributing to overall quality of life (Bishop, 2005; Livneh, 2001). The physical symptoms experienced by employees with chronic illness at work are often cited as reasons for resigning; however, there is research evidence to suggest that the real reasons for leaving employment include 'ugly organisational processes', which include a perceived lack of support and recognition of their contribution in the workplace (Vickers, 2008) leading to a reduced sense of personal efficacy (Johnson, Amtmann, Yorkston, Klasner, \& Kuehn, 2004). Participants in Vickers' (2008) phenomenological study of MS sufferers cited organisational factors as primary reasons for exiting employment rather than specifically disease-related symptoms or disabilities. It is difficult to determine the veracity of their claims in relation to organisational factors, but perceptions of their work environments clearly contributed to the decision to leave their jobs. Participants claimed they were 'fearful', 'scared', and 'paranoid' about organisational reactions to their condition. Reported barriers to participation in the workplace for employees with chronic illness frequently include perceptions of discrimination, lack of support from supervisors and fear of employment termination (Roessler et al., 2005). These responses indicate that sufferers of chronic illness may be subject to a decline in perceived psychological safety when considering their role, participation, and continuing employment in their organisations.

Psychological safety refers to employees' 'sense of being able to show and employ one's self without fear of negative consequences to self-image, status or career' (Kahn, 1990, p. 708). A psychologically safe work environment is characterised by feelings of safety, interpersonal trust and mutual respect (Baer \& Frese, 2003; Edmondson, 1999). The perception of a declining sense of psychological safety at work for the chronically ill may, in part, be explained with reference to response shift, which reflects a change in self-evaluation in regard to a target construct, such as quality of life, in relation to disease trajectory (Sprangers \& Schwartz, 1999). A change in health may cause someone to internally re-evaluate their functioning and personal resource pool in light of a chronic illness diagnosis. Mechanisms of a response shift include social comparisons and social support. The chronically ill often feel stigmatised and may come to feel at risk when comparing themselves to their perceived healthy colleagues in regard to direct or indirect discrimination, social isolation, and bullying (Vickers, 2000, 2008; Weitz, 1990). This experienced threat to the self may in turn discourage employees with chronic illness from participating in a broad range of socially based organisational activities that require them to extend themselves beyond prescribed job duties, in the absence of assurance that the performance of such behaviours will be acknowledged, respected and appreciated.

OCBs are positive or helping behaviours, such as assisting and supporting peers, facilitating teamwork, or promoting a favourable organisational image (Organ, 1988). OCBs are not required elements of job descriptions, nor are they compensated for by the formal reward system of the organisation. These 
behaviours are generally perceived as directed at the individual level towards colleagues (OCBIs) or more broadly towards the employing organisation (OCBOs) (Williams \& Anderson, 1991). In either form, OCBs entail the investment of personal resources in the performance of activities that are linked to job performance, job retention, morale, group cohesiveness, and a sense of belonging for workers (Podsakoff, MacKenzie, Paine, \& Bachrach, 2000).

The decision to invest personal resources in the performance of job-related behaviours such as OCBs will vary depending upon an employee's perception of the demands and risks involved. Studies based on Conservation of Resources (COR) theory have demonstrated that employees react differently to events that demand resourcefulness, depending upon individual perceptions of accessibility of personal resources (Hakanen, Perhoniemi, \& Toppinen-Tanner, 2008; Llorens, Schaufeli, Bakker, \& Salanova, 2007). This theory has particular relevance for employees with chronic illness given the response shift in self evaluation concerning personal resource availability.

\section{Conservation of Resources Theory}

Increasing recognition is being given to the role of psychological resources within current models of workplace stress and wellbeing, with respect to both the promotion of worker wellness, and the management of stress reactions (Bakker \& Schaufeli, 2008; Hobfoll, 2002). The basic tenet of COR theory applied to the work context (Westman, Hobfoll, Chen, Davidson, \& Laski, 2005) is that employees are motivated to obtain, foster and protect the things they value. These resources may be physical such as money or food, or they may be personal such as self-efficacy, optimism, or knowledge. Employees invest personal resources in order to gain additional resources, with stress reactions such as burnout occurring when resources are threatened or lost (Chen, Westman, \& Eden, 2009; Westman, et al., 2005).

Researchers have noted that personal resources may assume particular relevance for the work-related wellbeing of employees experiencing serious illness (Hakanen \& Lindbohm, 2008; Taskila, Martikainen, Hietanen \& Lindbohm, 2007). In a comparison of employed breast cancer survivors and their referents (Hakanen \& Lindbohm, 2008) both groups reported similar levels of work engagement in response to the provision of job resources (e.g., social support), but the personal resource of optimism was more strongly related to engagement for the former group. The results of their study indicate that fostering job resources will benefit the whole workplace in terms of work engagement, but that awareness needs to be directed towards the salience of specific personal resources such as optimism associated with the workrelated wellbeing of employees with particular health issues. Accordingly, the key issue for employees with chronic illness may not be the development of the cognitive affective state of work engagement in response to job resources, but the need to invest personal resources in the translation of felt engagement into the performance of work behaviours such as OCBs under conditions of a reduced sense of psychological safety. The perception of a psychologically safe work environment on the other hand is likely to facilitate the translation of work engagement into positive work outcomes such as OCBs, given the increased salience of this personal resource for the chronically ill. We therefore propose the following hypothesis:

\section{TABLE 1}

Gender, Age, Region and Occupation of the Sample

\begin{tabular}{|c|c|c|c|}
\hline & $\begin{array}{c}\mathrm{Cl} \\
\mathrm{N}=92 \\
\text { Frequency }\end{array}$ & $\begin{array}{c}\text { Non-Cl } \\
N=512 \\
\text { Frequency }\end{array}$ & $\begin{array}{c}\text { Total } \\
N=604\end{array}$ \\
\hline Age (mean, $S D$ ) & $43(11)$ & $41(12)$ & $41(11)$ \\
\hline $\begin{array}{l}\text { Male } \\
\text { Female }\end{array}$ & $\begin{array}{l}37 \% \\
63 \%\end{array}$ & $\begin{array}{l}46 \% \\
54 \%\end{array}$ & $\begin{array}{l}45 \% \\
55 \%\end{array}$ \\
\hline $\begin{array}{l}\text { Region } \\
\text { Metropolitan } \\
\text { Regional }\end{array}$ & $\begin{array}{l}62 \% \\
38 \%\end{array}$ & $\begin{array}{l}68 \% \\
32 \%\end{array}$ & $\begin{array}{l}67 \% \\
33 \%\end{array}$ \\
\hline $\begin{array}{l}\text { Occupation } \\
\text { Manager and administrator } \\
\text { Professional } \\
\text { Associate professional } \\
\text { Tradesperson and related worker } \\
\text { Clerical, sales, and service worker } \\
\text { Production and transport worker } \\
\text { Labourer and related worker } \\
\text { Other }\end{array}$ & $\begin{array}{c}16 \% \\
12 \% \\
19 \% \\
5 \% \\
30 \% \\
8 \% \\
5.5 \% \\
4.5 \%\end{array}$ & $\begin{array}{c}20 \% \\
19 \% \\
9 \% \\
9 \% \\
26 \% \\
5 \% \\
4 \% \\
8 \%\end{array}$ & $\begin{array}{c}19 \% \\
17 \% \\
10 \% \\
9 \% \\
27 \% \\
6 \% \\
4 \% \\
8 \%\end{array}$ \\
\hline Years tenure (mean, SD) & $7.9(8)$ & $7.08(8)$ & $7.21(8)$ \\
\hline
\end{tabular}


H1: The relationship between work engagement and the performance of OCBs (both OCBI and OCBO) will be mediated by perceptions of psychological safety for employees with chronic illness, in comparison to a referent group of general employees.

\section{Method}

\section{Subjects}

Participants were a random sample drawn from a national panel designed to be representative of the Australian population, based on data from the Australian Bureau of Statistics (ABS). The panel is maintained by a private organisation (Lightspeed Research), with respondents receiving financial compensation for survey completion (for further details regarding the panel process please contact the first author). Online panel surveys are increasingly being used in psychological and management research as a way to access large samples with wide geographic coverage (Evans \& Mathur, 2005). Li and Petrick (2008) suggest that online panel and traditional methodologies generate equivalent results, provided that the participants are screened for representational demographics and there is access to a good sample list of respondents who are frequent and experienced internet users. To be eligible for inclusion in the study participants had to be employed full-time ( $>34$ hours per week), to be aged 18 and over, to live in either regional Victoria or metropolitan Melbourne, and to have worked in their current position for at least two years. The average age of respondents was 41 years, with males representing $45 \%$ of the sample and females 55\%. Average length of tenure in their current position was 7.2 years. Primary occupations based on ABS categorisation are provided in Table 1.

\section{Procedure}

Following ethics approval the online survey was opened to panel members. Lightspeed Research maintains an online panel of 130,000 members across Australia, with 28,600 in regional Victoria and metropolitan Melbourne. An e-mail database is maintained by Lightspeed. E-mail requests for panel members to participate in the survey were sent out to the regional Victoria and metropolitan Melbourne panel members, explaining the broad purpose of the research and providing a link to the online survey site. Screening of online respondents continued until 604 participants meeting the eligibility criteria had been obtained. Fifteen per cent of respondents $(N=92)$ self-reported experiencing some form of chronic illness (e.g., Leukaemia, Parkinson's disease, depression). The demographics of this sub-sample are similar to the general sample, and are also provided in Table 1.

\section{Measures}

The survey contained general demographic questions (age, gender, occupation, tenure in current position) and the following measures:

Work Engagement. Work Engagement was measured using the 17 item Utrecht Work Engagement Scale (UWES; Livneh, 2001; Schaufeli, Salanova, GonzálezRomá, \& Bakker, 2002). In accordance with the procedure recommended by Schaufeli and Bakker (Schaufeli \& Bakker, 2010) the three dimensions of vigor (6 items), dedication (5 items) and absorption (6 items) were summed to create one work engagement score (Cronbach's alpha $=.95)$. Items were measured on a 7 -point scale $(1=$ Strongly disagree, $7=$ Strongly agree). A sample item for vigour is 'At my job I am very resilient, mentally'. A sample item for dedication is 'My job inspires me', and a sample item for absorption is 'Time flies when I'm working'.

Psychological Safety. Psychological Safety entails the beliefs organisational members hold in relation to the level that they feel psychologically safe in taking interpersonal risks in an organisational context such as speaking openly about issues that concern them or discussing failures. Psychological safety was measured using the 7-item scale developed by Edmondson (1999) and reworded to fit the organisational level by Baer and Frese (2003). Items were measured on a 5point scale $(1=$ Strongly disagree, $5=$ Strongly agree $)$. Sample items are 'In our company some employees are rejected for being different' and 'As an employee in our company, one is able to bring up problems and tough issues'. Cronbach's alpha for the scale $=.83$.

Organisational Citizenship Behaviour. Items for these measures consisted of the two scales developed by Lee and Allen (2002) to identify the beneficiary of the citizenship behaviour. OCBs were measured at the level of the individual (eight items, OCBI) and the Organisation (eight items, OCBO). Respondents were asked how often they engaged in these behaviours using 7 -point scales $(1=$ Never, $7=$ Always $)$. A sample of the OCBI scale is 'Give up time to help others who have work or non-work problems'. Cronbach's alpha for the scale $=.91$. A sample of the OCBO scale is 'Defend the organisation when others criticise it'. Cronbach's alpha for the scale $=.93$.

Chronic Illness. Rather than focusing on a specific CI diagnosis, the current study addressed the perceptions of employees with chronic illness in general. We did not obtain clinical diagnoses of chronic illness for this study, which would have been problematic within the large survey research design. For the purpose of this study our interest is primarily in employee perceptions of their own health status. To assess perceptions of illness status respondents were asked 'Do you suffer any form of chronic illness (Leukaemia, Parkinson's, depression etc)?' (Yes/No). 
TABLE 2

Means, Standard Deviations, and Zero-Order Correlations for the Study Variables

\begin{tabular}{lcccccc}
\hline & Alpha & $M$ & SD & 1. & 2. & 3. \\
\hline 1. WE & .95 & 80.0 & 18.8 & & & \\
2. Psychological safety & .83 & 23.5 & 5.3 & $.48^{* *}$ & $.60^{* *}$ & $.39^{* *}$ \\
3. OCBO & .93 & 37.5 & 9.9 & $.37 * *$ & $.18^{* *}$ & $.62^{* *}$ \\
4. OCBI & .91 & 40.7 & 8.2 & .37
\end{tabular}

Note: $N=604 ;{ }^{* *} p<.01$

\section{Results}

Means, standard deviations, Cronbach's alpha coefficients and zero order correlations for each of the study variables are reported in Table 2.

The relationship between work engagement, psychological safety and OCBO/OCBI was examined using a mediation regression analysis. The mediation regression analysis was conducted following the procedure recommended by Baron and Kenny (1986) and outlined in Tabachnick and Fidell (2001). To demonstrate mediation, four conditions must be satisfied. First, the total effect of the independent variable on the dependent variable must be significant. Second, the independent variable must be significantly related to the mediator. Third, the mediator still predicts the dependent variable after controlling for the independent variable; and fourth, the size of the relationship between the independent and dependent variables must be reduced after the mediator is entered into the model. Regressions for the chronic illness group and for the general employee group were conducted separately for each dependent variable; OCBO and OCBI.

\section{Chronic Illness Group}

A hierarchical regression analysis was used to examine conditions 1 and 3. Work Engagement was entered initially into the hierarchical regression to calculate the size of the direct effect on OCBO; the significant and positive relationship obtained $(\beta=.66 ; p<.001)$ satisfies the first condition for mediation (Table 3). In a separate analysis the significant and positive association between WE and Psychological Safety $(\beta=.50, p$ $<.01)$ satisfies the second condition for mediation.
Psychological Safety was added to the hierarchical regression and was a significant predictor of OCBO, thereby satisfying the third condition of mediation. The fourth and final condition for mediation involves establishing whether the relationship between the IV (WE) and the DV (OCBO) is reduced following the inclusion of the proposed mediator (Psychological Safety) in the regression equation. After the inclusion of Psychological Safety into the regression analysis, the effect of WE on OCBO was reduced from .66 to .47, remaining statistically significant $(p<.01)$ indicating partial mediation. In addition, a Sobel test for mediation indicated a significant reduction in the effect size of WE in the presence of Psychological Safety (Sobel test statistic $=3.75 ; p<.01)$. Overall, the final model was significant $(F=48.96 ; p<.01)$, explaining $51 \%$ of the variance in OCBO.

A hierarchical regression analysis was used to examine conditions 1 and 3. Work Engagement was entered initially into the hierarchical regression to calculate the size of the direct effect on OCBI; the significant and positive relationship obtained $(\beta=.43$; $p<.01)$ satisfies the first condition for mediation (Table 3). The significant and positive association between WE and Psychological Safety $(\beta=.50, p<$ .01) satisfies the second condition for mediation. Psychological Safety was added to the hierarchical regression and was a significant predictor of OCBI in the presence of WE (third condition). After the inclusion of Psychological Safety into the regression analysis, the effect of WE on OCBI was reduced from .43 to .30 , remaining statistically significant $(p<.01)$, satisfying the final step for partial mediation. The

TABLE 3

Summary of Hierarchical Regression Analysis Predicting Organisational Citizenship Behaviours for Chronically III Employees

\begin{tabular}{|c|c|c|c|c|c|c|c|c|c|c|c|c|}
\hline & \multicolumn{6}{|c|}{ OCBOs } & \multicolumn{6}{|c|}{ OCBls } \\
\hline & $B$ & SE B & $\beta$ & Adj. $R^{2}$ & $\mathrm{R}^{2} \Delta$ & $F \Delta$ & $B$ & SE B & $\beta$ & Adj. $R^{2}$ & $\mathrm{R}^{2} \Delta$ & $F \Delta$ \\
\hline Step 1 & & & & .42 & .43 & $67.84 * *$ & & & & .18 & .19 & $20.94^{\star *}$ \\
\hline Work engagement & .36 & 0.04 & $.66^{* \star}$ & & & & .16 & .03 & $.43^{* *}$ & & & \\
\hline Step 2 & & & & .51 & .09 & $17.58^{* *}$ & & & & .22 & .05 & $5.77 *$ \\
\hline Work engagement & .26 & 0.05 & $.47^{* *}$ & & & & .11 & .04 & $.30 * *$ & & & \\
\hline Psychological safety & .65 & 0.15 & $.35 * *$ & & & & .31 & .13 & $.26^{\star}$ & & & \\
\hline
\end{tabular}

Note: $N=92 ; * * p<.01 ; * p<.05$ 


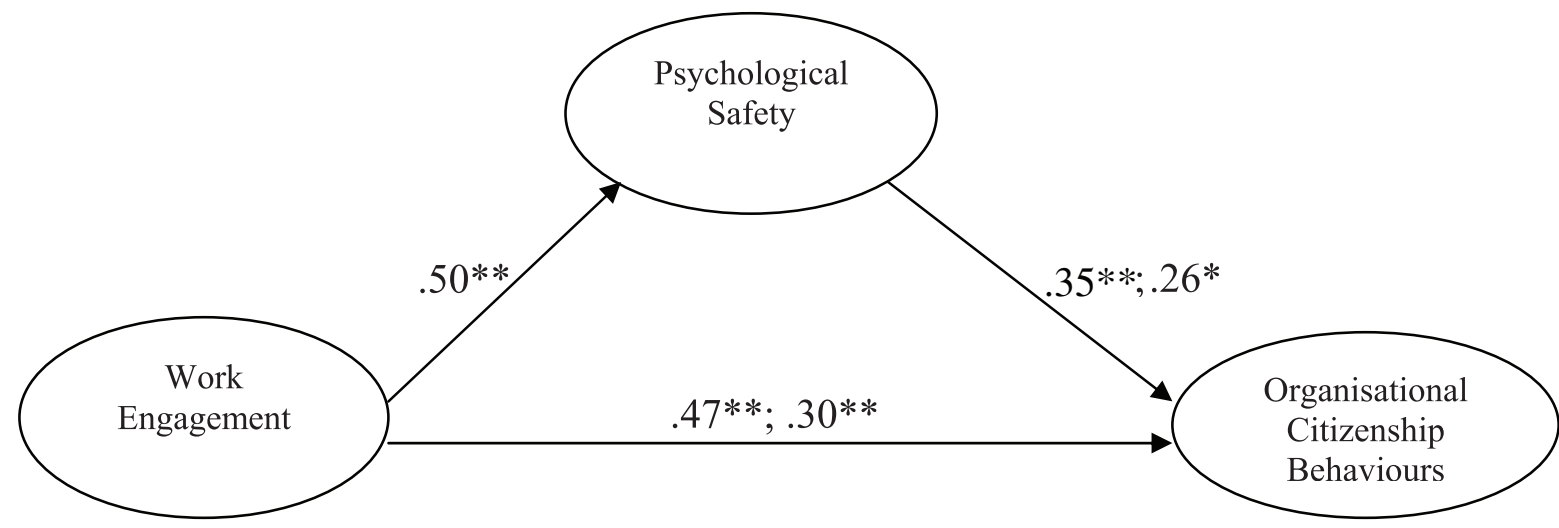

FIGURE 1

The research model.

Note: ${ }^{*} p<.01 ;{ }^{*} p<.05$; first estimates are OCBOs, second estimates are OCBIs.

Sobel test for mediation indicated a significant reduction in the effect size of WE in the presence of Psychological Safety (Sobel test statistic $=2.27 ; p<$ $.05)$. Overall, the final model was significant $(F=13.91$; $p<.01$ ), explaining $22 \%$ of the variance in OCBI.

\section{General Employee Group}

A hierarchical regression analysis was used to examine conditions 1 and 3. Work Engagement was entered initially into the hierarchical regression to calculate the size of the direct effect on OCBO; the significant and positive relationship obtained $(\beta=.59 ; p<.01)$ satisfies the first condition for mediation (Table 4). The significant and positive association between WE and Psychological Safety $(\beta=.47, p<.01)$ satisfies the second condition for mediation. Psychological Safety was added to the hierarchical regression and was not found to be a significant predictor of OCBO in the presence of $\mathrm{WE}$, therefore the third condition of mediation was not met. After the inclusion of Psychological Safety into the regression analysis, the effect of WE on OCBO was reduced from .59 to .56, remaining statistically significant $(p<.01)$. Overall, the final model was significant $(F=142.01 ; p<.01)$, explaining $36 \%$ of the variance in OCBO.

A hierarchical regression analysis was used to examine conditions 1 and 3. Work Engagement was entered initially into the hierarchical regression to calculate the size of the direct effect on OCBI; the significant and positive relationship obtained $(\beta=.37$; $p<.01)$ satisfies the first condition for mediation (Table 4). The significant and positive association between WE and Psychological Safety $(\beta=.47, p<$ .01) satisfies the second condition for mediation. Psychological Safety was added to the hierarchical regression and was not found to be a significant predictor of OCBI in the presence of WE, therefore the third condition of mediation was not met. After the inclusion of Psychological Safety into the regression anaysis, the effect of WE on OCBI increased from .37 to .39 , remaining statistically significant $(p<.01)$. Overall, the final model was significant $(F=41.39 ; p$ $<.01$ ), explaining $14 \%$ of the variance in OCBI.

\section{Discussion}

The results of the mediated regression analyses demonstrate support for our hypothesis; for both groups of employees, work engagement was significantly related to the performance of OCBs; however, psychological safety partially mediates the relationship between work engagement and OCBs for employees with chronic illness. In contrast, psychological safety was not significantly related to OCBs for the referent

TABLE 4

Summary of Hierarchical Regression Analysis Summary Predicting Organisational Citizenship Behaviours for General Employees

\begin{tabular}{|c|c|c|c|c|c|c|c|c|c|c|c|c|}
\hline & \multicolumn{6}{|c|}{ OCBOs } & \multicolumn{6}{|c|}{ OCBls } \\
\hline & $B$ & $S E B$ & $\beta$ & Adj. $R^{2}$ & $\mathrm{R}^{2} \Delta$ & $F \Delta$ & $B$ & $S E B$ & $\beta$ & Adj. $R^{2}$ & $\mathrm{R}^{2} \Delta$ & $F \Delta$ \\
\hline Step 1 & & & & .35 & .35 & $279.42 * *$ & & & & .14 & .14 & $81.97 * *$ \\
\hline Work engagement & .31 & .02 & $.59 * *$ & & & & .17 & .02 & $.37 * *$ & & & \\
\hline Step 2 & & & & .36 & .01 & 3.3 & & & & .14 & .001 & 0.84 \\
\hline Work engagement & .29 & .02 & $.56 * *$ & & & & .18 & .02 & $.39 * *$ & & & \\
\hline Psychological safety & .14 & .07 & .07 & & & & .07 & .07 & .04 & & & \\
\hline
\end{tabular}

Note: $N=512: * * * p<.01$ 
group of general employees. The same pattern of results was found for OCBOs and OCBIs, although the amount of variance explained for OCBOs was greater (51\% compared to $22 \%)$. Psychological safety does not fully mediate the relationship between engagement and OCBs, but does appear to represent a key mechanism underlying the relationship between these variables for employees with chronic illness. These findings are illustrated in the research model (see Figure 1).

The implications of these findings are that, for employees with chronic illness, being able to engage in behaviours that entail the use of personal resources and that may facilitate the development of their careers is significantly determined by the extent to which they feel safe to get involved and to which they feel trusted and respected in the workplace. In accordance with the propositions from COR theory (Hobfoll, 2002), the provision of a psychologically safe working environment for employees with chronic illness leads to a greater likelihood that these employees would seek opportunities to risk resource investment in the performance OCBs. The mechanisms that translate the experience of work engagement into positive work behaviours do, therefore, appear to differ for particular groups of employees, where perceptions of personal resource availability differ. This is particularly apparent in OCBs directed towards the employing organisation. Feeling safe to engage led to an increased likelihood of performing behaviours such as expressing loyalty towards the organisation, defending the organisation, and taking action to protect the organisation from prospective problems. There are a number of potential explanations for this finding, including the possibility that employees with chronic illness are more equity sensitive and are therefore more willing to engage in expressions of loyalty to their organisation in response to organisational expressions of support and respect. Participating and being involved in groups, including organisations, can have positive consequences for all employees (Portes, 1998); however, organisational participation may have elevated importance for employees with chronic illness as the capacity to engage in a broad range of outside referent groups may be impinged upon by illness or disability (Buunk, Collins, Taylor, VanYperen, \& Dakof, 1990; Davison, Pennebaker, \& Dickerson, 2000). There may also be economic implications behind the elevated importance of OCBOs, as any threat to continuing employment for employees with chronic illness will also have a direct impact on the economic and social wellbeing of their families. Employees with chronic illness may therefore become more acutely aware of the need to be seen as a loyal and functional member of the group.

The psychological safety scale used for the present study measured individual perceptions of the freedom to discuss ideas, make mistakes, take risks, seek help, rejection for being different, and raising problems and tough issues on a general organisational level. Although not specifically aimed at the chronically ill, the scale does adequately capture some of the challenges that those with chronic illness or disability may face when confronting issues of psychological safety at work. Whether it be due to the stigmatisation of employees with chronic illness, feelings of inadequacy, importance of referent groups, or economic or social consequences of being shunned, it is clear from the data that psychological safety is an important personal resource for employees with chronic illness when enacting on their willingness to engage in organisational activities. The findings suggest that employees with chronic illness may become acutely aware of any state of difference in terms of their health status, which may reflect a negative response shift (Sprangers \& Schwartz, 1999) to a target construct (work environment).

The implications of the findings of the current study are that organisational decision makers need to be cognisant of the management of the specific needs of employees with chronic illness through both nonlegislative and legislative processes. Work engagement for the chronically ill will lead to OCBs, and possibly enhanced job performance and employment continuance if the right job-level conditions exist. For employees with chronic illness, psychological safety is one such job condition. Legislative approaches to the promotion of a psychologically safe work environment primarily address the prevention of mental injury through initiatives aimed at reducing toxic work behaviours such as bullying or harassment (Shain, 2009). Dollard and Bakker (2010) for example operationalise psychological safety climate as policies, practices and procedures aimed at the protection of workers from psychological and social risk or harm. However, the promotion of positive workplace behaviours to enhance perceptions of safety, trust and respect requires a different approach based upon the principles of social inclusion, as inclusion is the antithesis of exclusion (being left out or pushed out) and discrimination. Simply, social inclusion means that individuals have the resources, opportunities and capabilities to learn, participate in the workforce, connect with others, and have a voice in relative matters (Sen, 1999; Australian Social Inclusion Board, 2010). For example, a report on employment in relation to MS sufferers reflected this in that after family support, the support of employers and other staff $(49 \%)$ was a determining factor in remaining employed (Chandraratna, 2010).

Future research needs to consider the ways in which programs drawing upon the principles of social inclusion can be voluntarily used by organisations to enhance workforce participation of employees with chronic illness, and indeed any group of employees who may be disadvantaged, as the implications of workforce participation extend beyond the workplace itself. For employees with chronic illness, being out of 
work exacerbates declining health status, family poverty and social exclusion, and increases overall damage to the communities in which these people live (Department for Work and Pensions and the Department of Health, 2008).

\section{Limitations and Conclusion}

The findings of the current study indicate that current models of work engagement need to address the role of specific personal resources in the translation of engagement into behaviours that enhance workforce participation for groups of employees with particular health issues. The use of a cross-sectional research design in the present study limits the extent to which firm conclusions can be drawn, and future research is required to extend the findings to employees with particular illnesses, as the salience of specific personal resources within the context of other aspects of workplace participation may well differ. We did not obtain information regarding the physical impact of employees' illnesses on their work, which may well differ substantially across different conditions and degree of illness. Similarly, as our interest in this study was concerned specifically with employees' perceptions of their own health status, we did not seek information on employees' perceptions of other employment conditions that may have impacted on their workforce participation. The current findings would also be strengthened by future research incorporating the perceptions of individuals who have had to leave the workforce due to factors associated with chronic illness. What is clear from the current results is that organisational procedures aimed at developing and maintaining a psychologically safe work environment need to consider not only the protection of employee mental health in general, but the promotion of psychosocial conditions that enable employees with chronic illness to fully participate and remain within a domain of functioning that contributes to their wellbeing.

\section{References}

Australian Institute of Health and Welfare. (2009). Chronic disease and participation in work (Cat. no. PHE 109). Canberra, Australia: Author.

Baer, M., \& Frese, M. (2003). Innovation is not enough: Climates for initiative and psychological safety, process innovations, and firm performance. Journal of Organizational Behavior, 24(1), 45-68.

Bakker, A.B., \& Schaufeli, W.B. (2008). Positive organizational behavior: Engaged employees in flourishing organizations. Journal of Organizational Behavior, 29(2), 147-154.

Banks, P., \& Lawrence, M. (2006). The Disability Discrimination Act, a necessary, but not sufficient safeguard for people with progressive conditions in the workplace? The experiences of younger people with Parkinson's disease. Disability \& Rehabilitation, 28(1), 13-24.

Baron, R.M., \& Kenny, D.A. (1986). The moderator-mediator variable distinction in social psychological research: Conceptual, strategic, and statistical considerations. Journal of Personality \& Social Psychology, 51(6), 1173-1182.
Beatty, J., \& Joffe, R. (2006). An overlooked dimension of diversity: The career effects of chronic illness. Organizational Dynamics, 35(2), 182-195.

Bishop, M. (2005). Quality of life and psychosocial adaptation to chronic illness and disability. Rehabilitation Counseling Bulletin, 48(4), 219-231.

Buunk, B.P., Collins, R.L., Taylor, S.E., VanYperen, N.W., \& Dakof, G.A. (1990). The affective consequences of social comparison: Either direction has its ups and downs. Journal of Personality and Social Psychology 59(6), 1238-1249.

Chandraratna, D. (2010). MSIF survey on employment and MS. London: Multiple Sclerosis International Federation.

Chen, S., Westman, M., \& Eden, D. (2009). Impact of enhanced resources on anticipatory stress and adjustment to new information technology: A field-experimental test of conservation of resources theory. Journal of Occupational Health Psychology, 14(3), 219-230.

Collins, J.J., Baase, C.M., Sharda, C.E., Ozminkowski, R.J., Nicholson, S., Billotti, G.M. ... Berger, M.L. (2005). The assessment of chronic health conditions on work performance, absence, and total economic impact for employers. Journal of Occupational \& Environmental Medicine, 47(6), 547-557.

Davison, K.P., Pennebaker, J.W., \& Dickerson, S.S. (2000). Who talks? The social psychology of illness support groups. American Psychologist, 55(2), 205-217.

Dean, B.B., Aguilar, D., Barghout, V., Kahler, K.H., Frech, F., Groves, D., \& Ofmann, J.J. (2005). Impairment in work productivity and health-related quality of life in patients with IBS. The American Journal of Managed Care, 11(1), S17-S26.

Demerouti, E., Bakker, A.B., Nachreiner, F., \& Schaufeli, W.B. (2001). The job demands-resources model of burnout. Journal of Applied Psychology, 86(3), 499-512.

Department for Work and Pensions and the Department of Health. (2008). Improving health and work: Changing lives. The Government's response to Dame Carol Black's review of the health of Britain's working-age population (Cm 7492). Surrey, UK: Office of Public Sector Information.

Dollard, M.F., \& Bakker, A.B. (2010). Psychosocial safety climate as a precursor to conducive work environments, psychological health problems, and employee engagement. Journal of Occupational \& Organizational Psychology, 83(3), 579-599.

Edmondson, A. (1999). Psychological safety and learning behavior in work teams. Administrative Science Quarterly, 44(2), 350-383.

Evans, J.R., \& Mathur, A. (2005). The value of online surveys. Internet Research, 15(2), 195-215.

Hakanen, J.J., \& Lindbohm, M. (2008). Work engagement among breast cancer survivors and the referents: The importance of optimism and social resources at work. Journal of Cancer Surivorship, 2(4), 283-295.

Hakanen, J.J., Perhoniemi, R., \& Toppinen-Tanner, S. (2008). Positive gain spirals at work: From job resources to work engagement, personal initiative and work-unit innovativeness Journal of Vocational behavior, 73(1), 78-91.

Hobfoll, S.E. (2002). Communal versus individualistic construction of sense of mastery in facing life challenges Journal of Social and Clinical Psychology 21(4), 362-399.

Johnson, K.L., Amtmann, D., Yorkston, K.M., Klasner, E.R., \& Kuehn, C.M. (2004). Medical, pyschological, social, and programmatic barriers to employment for people with multiple sclerosis. The Journal of Rehabilitation, 70(1), 38-50.

Kahn, W.H. (1990). Psychological conditions of personal engagement and disengagement at work. Academy of Management Journal, 33(4), 692-724. 
Lee, K., \& Allen, N.J. (2002). Organizational citizenship behavior and workplace deviance: The role of affect and cognition. Journal of Applied Psychology, 87(1), 131-142.

Leiter, M.P., \& Bakker, A.B. (2010). Work engagement: Introduction. In A.B. Bakker \& M.P. Leiter (Eds.), Work engagement: A handbook of theory and essential research (pp. 1-9). New York: Psychology Press.

Li, X., \& Petrick, J.F. (2008). Examining the antecedents of brand loyalty from an investment model perspective. Journal of Travel Research, 47(1), 25-34.

Livneh, H. (2001). Psychosocial adaptation to chronic illness and disability: A conceptual framework. Rehabilitation Counseling Bulletin, 44(3), 151-160.

Llorens, S., Schaufeli, W.B., Bakker, A.B., \& Salanova, M. (2007). Does a positive gain spiral of resources, efficacy beliefs and engagement exist? Computers in Human Behavior, 23(1), 825-841.

Maslach, C., Schaufeli, W.B., \& Leiter, M.P. (2001). Job burnout. Annual Review of Psychology, 52, 397-422.

Organ, D. (1988). Organizational citizenship behaviors: The good soldier syndrome. Lexington: Lexington Books.

Podsakoff, P.M., MacKenzie, S.B., Paine, J.B., \& Bachrach, D.G. (2000). Organizational citizenship behaviors: A critical review of the theoretical and empirical literature and suggestions for future research. Journal of Management, 26(3), 513-563.

Portes, A. (1998). Social capital: Its origins and applications in modern society. American Review of Sociology, 24(1), 1-24.

Roessler, R.T. (2003). Multiple sclerosis and employment barriers: A systemic perspective on diagnosis and intervention. Work, 21(1), 17-23.

Roessler, R.T., Turner, R.C., Robertson, J.L., \& Rumrill, P.D. (2005). Gender and perceived illness severity: Differential indicators of employment concerns for adults with multiple sclerosis? Rehabilitation Counseling Bulletin, 48(2), 66-74.

Saks, A.M. (2006). Antecedents and consequences of employee engagement. Journal of Managerial Psychology, 21(7), 600-619.

Salanova, M., Agut, S., \& Peiró, J. (2005). Linking organizational resources and work engagement to employee performance and customer loyalty: Mediation of service climate. Journal of Applied Psychology, , 90(6), 1217-1227.

Salanova, M., Schaufeli, W.B., Xanthopolou, D., \& Bakker, A.B. (2010). Engagement and human thriving: Complementary perspectives on energy and connenctions to work. In A.B. Bakker \& M.P. Leiter (Eds.), Work engagement: $A$ handbook of theory and essential research (pp. 132-146). New York: Psychology Press.
Schaufeli, W.B., \& Bakker, A.B. (2004). Job demands, job resources, and their relationship with burnout and engagement: A multisample study. Journal of Organizational Behavior, 25(3), 293-315.

Schaufeli, W.B., \& Bakker, A.B. (2010). Defining and measuring work engagement: Bringing clarity to the concept. In A.B. Bakker \& M.P. Leiter (Eds.), Work engagement: A handbook of essential theory and research (pp. 10-24). New York: Psychology Press.

Schaufeli, W.B., Salanova, M., González-Romá, V., \& Bakker, A.B. (2002). The measurement of engagement and burnout: A confirmative analytic approach. Journal of Happiness Studies, 3(1), 71-92.

Sen, A.K. (1999). Development as freedom. New York: Anchor Books.

Shain, M. (2009). Psychological safety at work: Emergence of a corporate and social agenda in Canada. International Journal of Mental Health Promotion, 11(3), 42-48.

Australian Social Inclusion Board. (2010). Social inclusion in Australia: How Australia is faring (2010). Canberra, Australia: Author.

Sprangers, M.A.G., \& Schwartz, C.E. (1999). Integrating response shift into health-related quality of life research: A theoretical model Social Science \& Medicine, 48(11), 1507-1515.

Tabachnick, B.G., \& Fidell, L.S. (2001). Using multivariate statistics (4th ed.). Boston: Allyn \& Bacon.

Taskila, T., Martikainen, R., Hietanen, P., \& Lindbohm, M. (2007). Comparative study of work ability between cancer survivors and their referents. European Journal of Cancer, 43(5), 914-920.

Vickers, M.H. (2000). Stigma, work, and 'unseen' illness: A case and notes to enhance understanding. Illness, Crisis, \& Loss, 8(2), 131-151.

Vickers, M.H. (2008). Why people with MS are really leaving work: From a Clayton's choice to an ugly passage - A phenomenological study. Review of Disability Studies: An International Journal 4(4), 43-57.

Weitz, R. (1990). Living with the stigma of AIDS. Qualitative Sociology, 13(1), 23-38.

Westman, M., Hobfoll, S.E., Chen, S., Davidson, O.B., \& Laski, S. (2005). Organizational stress through the lens of Conservation of Resources (COR) theory. In P.L. Perrewe \& D.C. Ganster (Eds.), Research in occupational stress and well-being (Vol. 4, pp. 167-220). Amsterdam: JAI.

Williams, L.J., \& Anderson, S.E. (1991). Job satisfaction and organizational commitment as predictors of organizational citizenship and in-role behaviors. Journal of Management, 17(3), 601-617. 